\title{
IMPLEMENTASI METODE WASPAS UNTUK MENENTUKAN IKAN TERI ASIN KERING BERKUALITAS TERBAIK
}

\author{
Aggy Pramana Gusman ${ }^{1)}$, Rindu Rafvia Linostu ${ }^{2}$, Surmayanti ${ }^{3)}$ \\ 1,2,3 Sistem Informasi, Universitas Putra Indonesia "YPTK" Padang, Indonesia \\ Email: ${ }^{1}$ Apgusman@gmail.com, ${ }^{2}$ linosturafviarindu@gmail.com, ${ }^{3}$ Surmayanti1994@gmail.com,
}

\begin{abstract}
For people who live on the coast, the sea / beach is a promising source of income to depend on life and Indonesia is a country that has a lot of coastal edges, one of which is the southern coast of West Sumatra, the people around depend on life by selling fish both fresh and fish marinated, especially marinated fish will get more benefits because of the preservation of the fish due to the tempting benefits, many residents process with origin or nonstandard processes so that salted fish do not last long compared to the salting process that meets the standards, UD LABA-LABA is an agent / dealer selling types of fish including salted fish, with the condition that many residents make salted fish that do not meet the standards, the Profit must be very careful to buy salted fish processed by residents because of its very short durability, of course if one buys will incur losses on the part of UD LABA-LABA, the Weight Aggregated Sum Product Assessment (WASPAS) Method is a method that can reduce errors or optimize the assessment for sorting highest and lowest values, this method is built and implemented in the form of a system to assist UD LABA-LABA in purchasing fish salted processed citizens, after applying to UD. LABA-LABA and generate a profit increase of $20 \%$ from before this method was implemented.
\end{abstract}

Keywords: Decision Support System, Information System, The Weight Aggregated Sum Product Assesment, WASPAS

\begin{abstract}
Abstrak
Pada masyarakat yang hidup di tepian pantai, lautan/pantai adalah sumber penghasilan yang menjanjikan untuk bergantung hidup dan Indonesia adalah negara yang memiliki banyak tepian pantai,. Salah satunya pesisir selatan di Sumatra Barat. Warga sekitar pantai menggantungkan hidup dengan menjual ikan baik ikan segar maupun ikan yang diasinkan, khusus ikan yang di asinkan akan mendapatkan keuntungan yang akan lebih banyak karena ke awetan ikan tersebut dikarenakan keuntungan yang mengiurkan tersebut banyak warga mengolah dengan proses asal-asalan atau tidak standar sehingga ikan asin tersebut tidak bertahan lama dibandingkan proses pengasinan yang memenuhi standar, UD LABA LABA adalah sebuah agen/bandar menjual jenis ikan termasuk ikan asin, dengan kondisi banyaknya warga yang membuat ikan asin yang tidak memenuhi standar maka UD LABA LABA harus hati hati sekali untuk membeli ikan asin olahan warga di karenakan keawetannya yang sangat sebentar, tentunya jika salah membeli akan menimbulkan kerugian di pihak UD LABA LABA. Untuk menyelesaikan permasalalahan tersebut maka diperlukan Sistem Pendukung Keputusan dengan Metode Weight Aggregated Sum Product Assesment (WASPAS). Metode WASPAS dalah metode yang dapat mengurangi kesalahan-kesalahan atau mengoptimalkan dalam penaksiran untuk pemililahan nilai tertinggi dan terendah (Handayani, M., Marpaung, N., \& Anggraini, S. (2019)), metode ini dibangun dan di implementasikan dalam bentuk sistem untuk membantu UD LABALABA dalam membeli ikan asin olahan warga. Kriteria yang digunakan yaitu ukuran ikan, warna ikan, aroma ikan, tektur ikan dan daya tahan ikan. Penerapan sistem ini menghasilkan kenaikan keuntungan 20\% dari sebelum sistem di terapkan.
\end{abstract}

Kata Kunci: Sistem Pendukung Keputusan, Sistem Informasi, Weight Aggregated Sum Product Assesment, WASPAS.

\section{Pendahuluan}

Perkembangan teknologi dan informasi sangat berperan penting untuk menunjang aktivitas seharihari, baik dalam bidang bisnis, hiburan, pendidikan, pemerintahan dan lain sebagainya (Wedyawati, V. (2019)). Informasi dapat digunakan untuk membantu pengambilan keputusan (Decision Support System) mulai dari mengidentifikasi masalah, memilih data yang relevan, menentukan pendekatan yang digunakan dalam proses pengambilan keputusan, dan mengevaluasi pemilihan alternatif, penilaian, perubahan kriteria serta perubahan nilai bobot (Handayani \& Marpaung, 2018).

Metode WASPAS (Weight Aggregated Sum Product Assesment) merupakan metode yang dapat mengurangi kesalahan - kesalahan atau mengoptimalkan dalam penaksiran untuk pemilihan nilai tertinggi dan terendah (Zalukhu, Y., \& Zay, R. 
A.2018 ). Metode ini merupakan kombinasi unik dari pendekatan MCDM yaitu model jumlah tertimbang (Weight Sum Model/WSM) dan model produk tertimbang (Weight Product Model/WPM). Pada awalnya membutuhkan normalisasi linier dari elemen matriks keputusan dengan menggunakan dua persamaan (Bengnga, A., \& Pakaya, N. 2017).

UD. Laba-laba merupakan usaha rumahan yang mengolah ikan teri segar menjadi ikan teri asin kering. Agar tidak rusak atau busuk, ikan teri segar langsung direbus yang dicampur dengan garam di tengah laut karena dibutuhkan waktu tempuh yang cukup lama untuk mencapai daratan Patang, P., \& Yunarti, Y. (2014). Namun secara umum proses pengolahan ikan teri asin kering secara tradisional kurang memperhatikan aspek sanitasi dan kehigienisan dalam proses persiapan, pengolahan dan penyimpanan produk. Akibatnya adalah hasil olahan ikan teri asin kering akan mudah mengalami kerusakan secara mikrobiologis dan kimiawi Akbardiansyah, A., Desniar, D., \& Uju, U. (2018). Melihat kenyataan yang terjadi didalam industri pengolahan ikan teri asin kering, maka harus dicari jalan keluar yang tepat agar proses pengolahan ikan teri asin kering dapat menghasilkan produk yang terbaik.

Penelitian sejenis juga pernah diteliti oleh Ulva, A., Iqbal, D., Nuraini, N., Mesran, M., Sutiksno, D. U., \& Yuhandri, Y. (2018, July). Untuk mencari bibit lele terbaik untuk di budidayakan. Dari hasil penelitian diatas maka dapat diambil beberapa kesimpulan antara lain: Untuk kedua metode didalam Sistem Pendukung Keputusan dalam hal ini adalah metode MOORA dan metode WASPAS dapat digunakan dalam pengambilan keputusan pemilihan bibit lele terbaik. Setelah melakukan perbandingan untuk masingmasing bobot metode MOORA dan metode WASPAS maka dapat disimpulkan bahwa penjumlahan menggunakan metode MOORA lebih cepat, tepat dan mudah dalam menghasilkan nilai alternatif, sehingga metode MOORA adalah metode yang paling efektif untuk menyelesaikan kasus tersebut.

Untuk mendapatkan kriteria yang diinginkan maka dibutuhkan sistem pengambilan keputusan yang berbasiskan komputer umtuk membantu dalam penentuan kritieria ikan teri agar mendapatkan output ikan teri asin kering berkualitas terbaik. Berdasarkan latar belakang diatas, peneliti tertarik untuk melakukan penelitian, dengan judul "Pengimplementasian Metode WASPAS dalam Perancangan Sistem Pengambilan Keputusan untuk Menentukan Ikan Teri Asin Kering Berkualitas Terbaik pada UD. Laba-laba Berbasis Web".

\section{Metode Penelitian}

\subsection{Metode Weighted Aggregated Sum Product}

\section{Assesment (WASPAS)}

Metode Weighted Aggregated Sum Product Assesment (WASPAS) merupakan metode yang dapat mengurangi kesalahan-kesalahan atau mengoptimalkan dalam penaksiran untuk pemilihan nilai tertinggi dan terendah. Metode ini merupakan kombinasi unik dari pendekatan MCDM yaitu model jumlah tertimbang (Weight Sum Model/WSM) dan model produk tertimbang (Weight Product Model/WPM) (Ickhsan, M., Anggraini, D., Haryono, R., Sahir, S. H., \& Rohminatin, R. (2018)). Pada awalnya membutuhkan normalisasi linier dari elemen matriks keputusan dengan menggunakan dua persamaan.

Langkah-langkah metode weighted aggregated sum product assesment (WASPAS) adalah sebagai berikut:

a. Menentukan normalisasi matriks dalam pengambilan keputusan

$\begin{array}{rrr}X 11 & X 12 & X 1 n \\ =X 21 & X 22 & X 2 n \\ X m 1 & X m 2 & X m n \\ \ldots \ldots \ldots . . .[1] & \end{array}$

$X i j$

b. Jika nilai maksimal dan minimal ditentukan, maka persamaan menjadi sebagai berikut:

kriteria benefit, maka :

Jika

$R i j=\frac{X_{i j}}{\operatorname{Max}_{x i j}}$

kriteria cost, maka :

Jika

$R i j=\frac{\operatorname{Min}_{x i j}}{X_{i j}}$

c. Menghitung nilai normalisasi matriks dan bobot weighted aggregated sum product assesment (WASPAS) dalam pengambilan keputusan.

$$
\begin{aligned}
& \mathrm{Qi}=0,5 \\
& \sum_{j=0}^{n} R_{i j} W j+0,5 \prod_{i=1}^{n}\left(R_{i j}\right) W j \quad \ldots \ldots \ldots \\
& \text { [4] } \\
& \text { (Suginam, S., Nasution, E. S., Lubis, } \\
& \text { S. U., \& Mesran, M. (2018, October) }
\end{aligned}
$$




\subsection{Analisa}

Dalam proses analisa terdapat dua tahap analisa yang harus dilakukan. Tahapan tersebut adalah:

a. Analisa data

Pada tahap analisa data ini dilakukan setelah melakukan pengumpulan data dan informasi-informasi yang telah diambil melalui wawancara langsung kepada patani pengolah ikan asin secara tradisional serta warga yang dianggap pakar dalam urusan pengolahan ikan asin. Tahap analisa data ini suatu proses mengolah data untuk memperoleh langkah-langkah yang akan digunakan selama melakukan perancangan agar sesuai dengan harapan tujuan penelitian.

b. Analisa Sistem

Analisa sistem merupakan dasar dalam merencanakan dan merancangkan sistem yang akan diterapkan menggunakan metode weighted aggregated sum product assesment (WASPAS). Dimana program yang akan dibuat menggunakan bahasa pemrograman PHP dan Database Mysql.

\subsection{Perancangan}

Tahapan perancangan bertujuan untuk membuat penelitian dirancang sesuai dengan tujuannnya, sehingga tidak melenceng dari tujuan penelitian serta proses pengumpulan data-data yang akan dilakukan untuk mendukung perancangan sistem sebagai objek penelitian. Perancangan akan menggunakan Unified Modeling Language (UML) sebagai model rancangan agar terorganisasi dan terstruktur dengan rancangan.

\subsection{Implementasi}

Implementasi sistem merupakan tahap meletakkan sistem sehingga siap untuk dioperasikan. Pada tahap ini perancangan sistem dilakukan dengan menggunakan bahasa pemrograman PHP dan Database MySQL.

\subsection{Pengujian Sistem}

Pengujian bertujuan untuk melakukan koreksi terhadap sistem yang telah dibangun berdasarkan tingkat efisiensi sistem sebagai solusi dalam pemecahan masalah-masalah yang telah dirumuskan. Pengujian sistem merupakan tahap akhir dalam melakukan testing guna untuk mengetahui kesalahan dalam sistem tersebut. Pengujian dilakukan dengan melihat apakah sistem tersebut sudah berjalan dengan benar dan sesuai dengan perancangan yang dilakukan.

\section{Pembahasan}

\subsection{Analisa Data}

3.1.1 Perhitungan Metode Waspas

Dalam prosesnya, metode WASPAS terdiri dari beberapa langkah, adapun data kriteria yang digunakan dalam penentuan ikan teri asin kering berkualitas terbaik adalah seperti pada Tabel 3.1 berikut:

Tabel 1. Data Kriteria Penilaian

\begin{tabular}{c|c|c|c|c}
\hline No & $\begin{array}{c}\text { Kode } \\
\text { Kriteria }\end{array}$ & Nama Kriteria & Bobot & Atribut \\
\hline 1 & C1 & Ukuran Ikan & 2 & Cost \\
2 & C2 & Warna Ikan & 3 & Benefit \\
3 & C3 & Aroma Ikan & 3 & Benefit \\
4 & C4 & Tekstur Ikan & 4 & Benefit \\
5 & C5 & $\begin{array}{c}\text { Daya Tahan } \\
\text { Simpan Ikan }\end{array}$ & 3 & Benefit \\
\hline
\end{tabular}

Setelah didapat data kriteria, langkah selanjutnya adalah menentukan nilai dari masing-masing kriteria seperti pada Tabel 3.2 berikut:

Tabel 2. Nilai Data Kriteria

\begin{tabular}{|c|c|c|}
\hline $\begin{array}{c}\text { Nama } \\
\text { Kriteria }\end{array}$ & Keterangan & Nilai \\
\hline \multirow{3}{*}{$\begin{array}{l}\text { Ukuran } \\
\text { Ikan }\end{array}$} & Kecil & 5 \\
\hline & Sedang & 3 \\
\hline & Besar & 1 \\
\hline \multirow{3}{*}{$\begin{array}{c}\text { Warna } \\
\text { Ikan }\end{array}$} & Alami (Kekuningan dan Kering) & 5 \\
\hline & Putih Pucat & 3 \\
\hline & Kuning Kecoklatan & 1 \\
\hline \multirow{3}{*}{$\begin{array}{c}\text { Aroma } \\
\text { Ikan }\end{array}$} & $\begin{array}{c}\text { Bau Segar seperti Bau Laut } \\
\text { (Amis) }\end{array}$ & 5 \\
\hline & Bau Busuk & 3 \\
\hline & $\begin{array}{l}\text { Tidak Berbau (Bisa Jadi } \\
\text { Mengandung Formalin) }\end{array}$ & 1 \\
\hline \multirow{3}{*}{$\begin{array}{l}\text { Tekstur } \\
\text { Ikan }\end{array}$} & Utuh & 5 \\
\hline & Kepala dan Badan Ikan Terpisah & 3 \\
\hline & Hancur & 1 \\
\hline \multirow{3}{*}{$\begin{array}{c}\text { Daya } \\
\text { Tahan } \\
\text { Simpan } \\
\text { Ikan }\end{array}$} & 10 Hari & 5 \\
\hline & Lebih dari 10 Hari & 3 \\
\hline & Lebih dari 1 Bulan & 1 \\
\hline
\end{tabular}

Selanjutnya, untuk data alternatif dilakukan pengujian sebanyak 3 orang pemasok, adapun alternatif yang digunakan dilihat pada Tabel 3.3 berikut: 
Tabel 3. Data Alternatif

\begin{tabular}{c|c}
\hline $\begin{array}{c}\text { Kode } \\
\text { Alternatif }\end{array}$ & $\begin{array}{c}\text { Nama } \\
\text { Pemasok } \\
\text { (Alternatif) }\end{array}$ \\
\hline A1 & Buk Rina \\
Nose \\
A2 & Mas Budi \\
& Anduk \\
A3 & Pak Yosef \\
\hline
\end{tabular}

Data kriteria dan data alternatif yang telah dianalisa, selanjutnya dilakukan proses perhitungan menggunakan metode weighted aggregated sum product assesment (WASPAS). Untuk proses metode WASPAS ini akan dilakukan pengujian Terhadap data uji seperti pada Tabel 4.4 berikut:

Tabel 4. Data Uji

\begin{tabular}{|c|c|c|c|c|c|c|}
\hline No & Alternatif & $\mathrm{C1}$ & $\mathrm{C2}$ & $\mathrm{C3}$ & $\mathrm{C4}$ & C5 \\
\hline 1 & $\begin{array}{l}\text { Ikan Asin } \\
\text { Buk Rina }\end{array}$ & $\begin{array}{c}\text { Keci } \\
1\end{array}$ & $\begin{array}{c}\text { Puti } \\
\text { h } \\
\text { Puca } \\
\text { t }\end{array}$ & $\begin{array}{c}\text { Bau } \\
\text { Sega } \\
\text { r } \\
\text { sepe } \\
\text { rti } \\
\text { Bau } \\
\text { Laut } \\
\text { (Am } \\
\text { is) }\end{array}$ & $\begin{array}{c}\text { Kepal } \\
\text { a dan } \\
\text { Bada } \\
n \\
\text { Ikan } \\
\text { Terpi } \\
\text { sah }\end{array}$ & $\begin{array}{c}\text { Leb } \\
\text { ih } \\
\text { dari } \\
1 \\
\text { Bul } \\
\text { an }\end{array}$ \\
\hline 2 & $\begin{array}{l}\text { Ikan Asin } \\
\text { Mas Budi }\end{array}$ & $\begin{array}{c}\text { Keci } \\
1\end{array}$ & $\begin{array}{c}\text { Ala } \\
\text { mi } \\
\text { (Kek } \\
\text { unin } \\
\text { gan } \\
\text { dan } \\
\text { Keri } \\
\text { ng) }\end{array}$ & $\begin{array}{c}\text { Bau } \\
\text { Bus } \\
\text { uk }\end{array}$ & Utuh & $\begin{array}{c}\text { Leb } \\
\text { ih } \\
\text { dari } \\
10 \\
\text { Har } \\
\text { i }\end{array}$ \\
\hline 3 & $\begin{array}{l}\text { Ikan Asin } \\
\text { Pak Yosef }\end{array}$ & $\begin{array}{c}\text { Seda } \\
\text { ng }\end{array}$ & $\begin{array}{c}\text { Ala } \\
\text { mi } \\
(\text { Kek } \\
\text { unin } \\
\text { gan } \\
\text { dan } \\
\text { Keri } \\
\text { ng) }\end{array}$ & $\begin{array}{c}\text { Bau } \\
\text { Sega } \\
\text { r } \\
\text { sepe } \\
\text { rti } \\
\text { Bau } \\
\text { Laut } \\
\text { (Am } \\
\text { is) }\end{array}$ & $\begin{array}{c}\text { Kepal } \\
\text { a dan } \\
\text { Bada } \\
\text { n } \\
\text { Ikan } \\
\text { Terpi } \\
\text { sah }\end{array}$ & $\begin{array}{c}\text { Leb } \\
\text { ih } \\
\text { dari } \\
10 \\
\text { Har } \\
\text { i }\end{array}$ \\
\hline
\end{tabular}

Dari data diatas, maka dilakukan penyesuaian data kriteria kedalam nilai data kriteria atau disebut dengan matriks keputusan seperti pada Tabel 3.5 berikut:

Tabel 5. Matriks Keputusan

\begin{tabular}{c|c|c|c|c|c}
\hline Alternatif & C1 & C2 & C3 & C4 & C5 \\
\hline Ikan Asin Buk Rina & 5 & 3 & 5 & 3 & 1 \\
Ikan Asin Mas Budi & 5 & 5 & 3 & 5 & 3 \\
Ikan Asin Pak Yosef & 3 & 5 & 5 & 3 & 3 \\
\hline
\end{tabular}

Selanjutnya, dari matriks keputusan ditentukan nilai tertinggi dan terendah untuk setiap kriteria. Adapun nilai maksimal dan minimal setiap kriteria dapat dilihat pada Tabel 3.6 berikut:

Tabel 6. Nilai Maksimal dan Minimal Matriks

\begin{tabular}{c|c|c|c|c|c}
\multicolumn{7}{c}{ Keputusan } \\
\hline $\begin{array}{c}\text { Nilai } \\
\text { Max }\end{array}$ & 5 & 5 & 5 & 5 & 3 \\
\hline $\begin{array}{c}\text { Nilai } \\
\text { Min }\end{array}$ & 3 & 3 & 3 & 3 & 1 \\
\hline
\end{tabular}

Langkah selanjutnya adalah melakukan normalisasi untuk setiap nilai matrik keputusan. Untuk melakukan normalisasi nilai, maka dapat melakukan proses sebagai berikut:

a. Untuk kriteria dengan tipe benefit, dihasilkan nilai normalisasi sebagai berikut:

Rumus untuk tipe benefit $: \boldsymbol{R} i \boldsymbol{j}=\frac{\boldsymbol{X}_{\boldsymbol{i j}}}{\boldsymbol{M a x}_{\boldsymbol{x} i \boldsymbol{j}}}$

$$
\begin{aligned}
& \text { Nilai MAX }=5 \\
& \mathrm{R} 21=\frac{3}{5}=0,6 \\
& \mathrm{R} 22=\frac{5}{5}=1 \\
& \mathrm{R} 23=\frac{5}{5}=1
\end{aligned}
$$

Nilai MAX $=5$

$$
\begin{aligned}
& \mathrm{R} 31=\frac{5}{5}=1 \\
& \mathrm{R} 32=\frac{3}{5}=0,6 \\
& \mathrm{R} 33=\frac{5}{5}=1
\end{aligned}
$$

Nilai MAX $=5$

$\mathrm{R} 41=\frac{3}{5}=0,6$

$\mathrm{R} 42=\frac{5}{5}=1$

$\mathrm{R} 43=\frac{3}{5}=0,6$

Nilai MAX $=3$

$$
\begin{aligned}
& \mathrm{R} 51=\frac{1}{3}=0,333 \\
& \mathrm{R} 52=\frac{3}{3}=1 \\
& \mathrm{R} 53=\frac{3}{3}=1
\end{aligned}
$$

b. Sedangkan untuk kriteria dengan tipe cost, dihasilkan nilai normalisasi sebagai berikut:

Rumus untuk tipe cost $: \boldsymbol{R} \boldsymbol{i j}=\frac{\boldsymbol{M i n}_{\boldsymbol{x} i \boldsymbol{j}}}{\boldsymbol{X}_{\boldsymbol{i j}}}$

$$
\begin{aligned}
& \text { Nilai MIN }=3 \\
& \mathrm{R} 11=\frac{3}{5}=0,6 \\
& \mathrm{R} 12=\frac{3}{5}=0,6 \\
& \mathrm{R} 13=\frac{3}{3}=1
\end{aligned}
$$

Setelah mendapatkan nilai normalisasi setiap alternatif, maka selanjutnya ditentukan hasil nilai 
alternatif (Qi). Adapun proses untuk mencari nilai Qi dapat dilihat pada proses berikut:

(Qi):

Rumus untuk menghitung nilai alternatif

$$
\mathrm{Qi}=0,5 \sum_{j=0}^{n} R_{i j} W j+0,5 \prod_{i=1}^{n}\left(R_{i j}\right) W j
$$

Nilai Qi yang terbaik merupakan nilai tertinggi.

$$
\begin{aligned}
& \mathrm{Q} 1=\left(0,5 \sum(0,6 * 2)+(0,6 * 3)+(1 * 3)+\right. \\
& (0,6 * 4)+(0,333 * 3)) \\
& \quad+\left(0,5 \Pi(0,6)^{2} *(0,6)^{3} *(1)^{3} *(0,6)^{4} *\right. \\
& \left.(0,333)^{3}\right) \\
& \quad=4,700 \\
& \text { Q2 } \quad\left(0,5 \sum(0,6 * 2)+(1 * 3)+(0,6 * 3)+\right. \\
& (1 * 4)+(1 * 3)) \\
& \quad+\left(0,5 \quad \prod(0,6)^{2} *(1)^{3} *(0,6)^{3} *(1)^{4} *\right. \\
& \left.(1)^{3}\right) \\
& \quad=6,539 \\
& \quad=\left(\quad 0,5 \sum(1 * 2)+(1 * 3)+(1 * 3)+\right. \\
& (0,6 * 4)+(1 * 3)) \\
& \quad+\left(0,5 \prod(1)^{2} *(1)^{3} *(1)^{3} *(0,6)^{4} *(1)^{3}\right) \\
& \quad=6,765
\end{aligned}
$$

Dari hasil proses pencarian nilai Qi, maka dapat dilakukan perangkingan pada hasil tersebut seperti pada Tabel 3.7 berikut:

Tabel 7. Perangkingan Hasil Metode WASPAS

\begin{tabular}{c|c|c}
\hline No & Alternatif & Nilai Alternatif Qi \\
\hline 1 & $\begin{array}{c}\text { Ikan Asin Pak } \\
\text { Yosef }\end{array}$ & 6,765 \\
2 & $\begin{array}{c}\text { Ikan Asin } \\
\text { Mas Budi }\end{array}$ & 6,539 \\
3 & $\begin{array}{c}\text { Ikan Asin } \\
\text { Buk Rina }\end{array}$ \\
\hline
\end{tabular}

\subsection{Analisa Sistem}

\section{a. Use Case Diagram}

Use case diagram merupakan jenis diagram perilaku yang didefinisikan dan diciptakan dari analisa kasus. Tujuannya adalah untuk menyajikan gambaran grafis dari fungsionalitas yang disediakan oleh sistem dalam hal pelaku, tujuan mereka (direpresentasikan sebagai kasus penggunaan), dan setiap ketergantungan antara kasus-kasus digunakan.

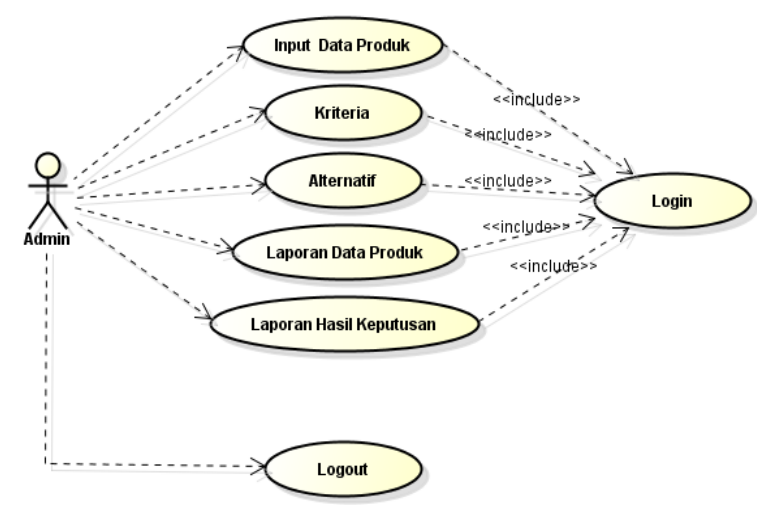

Gambar 1. Use Case Diagram

b. Activity Diagram

Activity diagram menggambarkan berbagai alir aktivitas dalam sistem yang sedang dirancang, bagaimana masing-masing alir berawal, decision yang mungkin terjadi, dan bagaimana mereka berakhir. Activity diagram juga dapat menggambarkan proses paralel yang mungkin terjadi pada beberapa eksekusi.

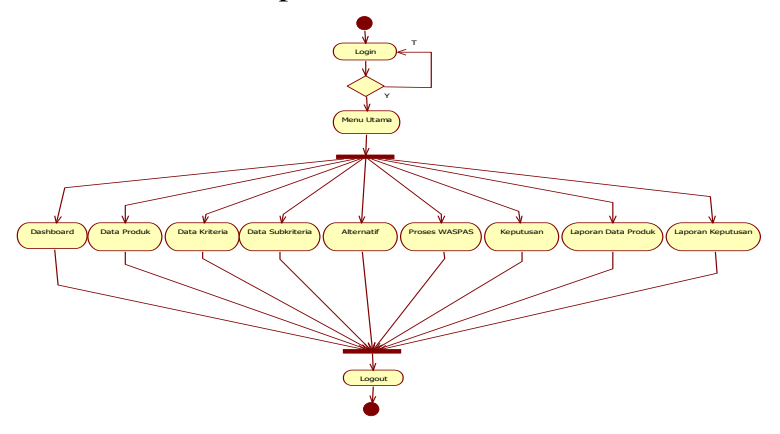

Gambar 2. Activity Diagram

\section{Implementasi Sistem}

Implementasi sistem merupakan salah satu tahap dalam pengembangan sistem informasi, dimana tujuannya adalah untuk meletakkan sistem informasi yang siap untuk dioperasikan.

\subsection{Form Menu Utama}

Form menu utama adalah antar muka (interface) yang digunakan sebagai form induk atau form utama. Tampilan form menu utama menampilkan sub menu yang terdiri dari data produk ikan asin, data kriteria, data subkriteria, alternatif, proses metode WASPAS, hasil keputusan, laporan dan menu keluar. 


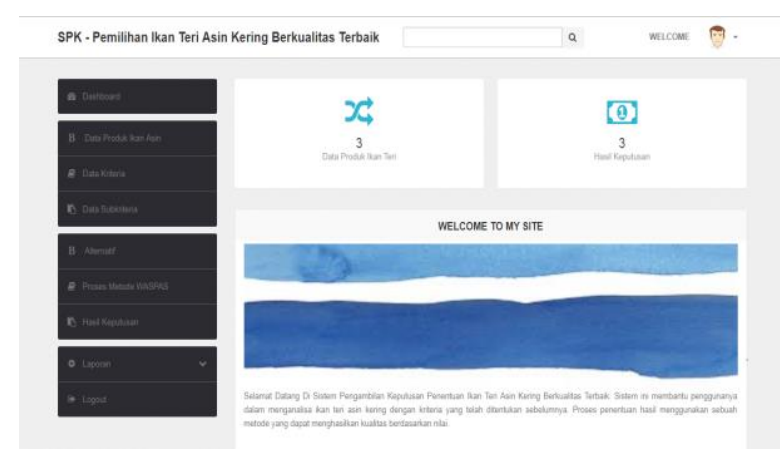

Gambar 3. Form Menu Utama

\subsection{Form Laporan Data Produk}

Form laporan data produk adalah laporan dari data produk yang sudah diinputkan.

\section{UD. LABA - LABA}

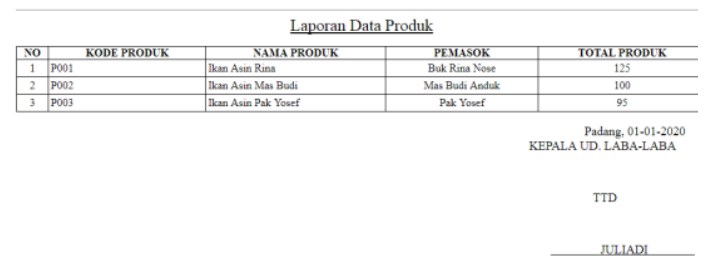

Gambar 4. Form Laporan Data Produk

\subsection{Form Laporan Hasil Keputusan Metode} WASPAS

Form laporan hasil keputusan metode WASPAS adalah laporan dari hasil keputusan dari metode WASPAS yang sudah didapatkan.

$$
\text { UD. LABA - LABA }
$$

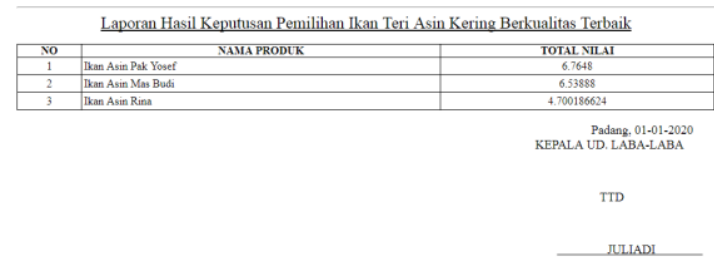

Gambar 5. Form Laporan Hasil Keputusan Metode WASPAS

\section{Kesimpulan}

Berdasarkan analisa yang telah dilakukan penulis, maka dapat ditarik kesimpulan Sistem pengambilan keputusan dengan menggunakan metode WASPAS (Weight Aggregated Sum Product Assesment) yang di bangun dalam bentuk aplikasi yang berguna dalam menunjang keputusan bandar ikan UD laba laba dalam membeli ikan asin olahan warga, sitem ini dapat memproses 5 kriteria yaitu Ukuran ikan, warna ikan, aroma ikan, tektur ikan dan daya tahan ikan, dengan system ini Ud laba laba bisa meminimalkan kesalahan dalam membeli ikan dari olahan warga, sistem ini dibuat dengan GUI yang sangat Friendly seingga tidak memerlukan pemilik UD turun tangan langsung untuk mencek hasil olahan ikan yang akan di beli.

Sitem ini telah di terapkan di UD laba -laba selama 30 hari, hasil dari diterapkan system ini UD laba laba mendapatkan penambahan pendapatan pembalian dari pelanggan sebanyak $20 \%$.

\section{DAFTAR PUSTAKA}

Handayani, M., Marpaung, N., \& Anggraini, S. (2019, September). Implementasi Metode Weighted Aggregated Sum Product Assesment (WASPAS) Dalam Pemilihan Karyawan Terbaik Berbasis Sistem Pendukung Keputusan. In Prosiding Seminar Nasional Riset Information Science (SENARIS) (Vol. 1, pp. 1098-1106).

Bengnga, A., \& Pakaya, N. (2017). Sistem Pendukung Keputusan Pemilihan Peserta Kapal Pemuda Nusantara dengan Menggunakan Metode Weighted Product (Wp). ILKOM Jurnal Ilmiah, 9(3), 331-337.

Patang, P., \& Yunarti, Y. (2014). KAJIAN PEMBERIAN BERBAGAI DOSIS GARAM TERHADAP KUALITAS IKAN BANDENG (CHANOS CHANOS SP.) ASIN KERING. JURNAL GALUNG TROPIKA, 3(3), 171-178.

Handayani, M., \& Marpaung, N. (2018, September). IMPLEMENTASI METODE WEIGHT AGGREGATED SUM PRODUCT ASSESMENT (WASPAS) DALAM PEMILIHAN KEPALA LABORATORIUM. In Seminar Nasional Royal (SENAR) (Vol. 1, No. 1, pp. 253-258).

Akbardiansyah, A., Desniar, D., \& Uju, U. (2018). Karakteristik Ikan Asin Kambing-Kambing (Canthidermis Maculata) dengan Penggaraman Kering. Jurnal Pengolahan Hasil Perikanan Indonesia, 21(2), 347-357.

Ulva, A., Iqbal, D., Nuraini, N., Mesran, M., Sutiksno, D. U., \& Yuhandri, Y. (2018, July). Sistem Pendukung Keputusan Pemilihan Bibit Lele Terbaik Menggunakan Metode MOORA (Multi-Objective Optimization On The Basis Of Ratio Analysis) dan WASPAS (Weight Aggregated Sum Product Assesment). In Seminar Nasional Sains dan Teknologi Informasi (SENSASI) (Vol. 1, No. 1).

Zalukhu, Y., \& Zay, R. A. (2018, August). Sistem Pendukung Keputusan Kelayakan Penerima Rehap Sekolah Menggunakan Metode WASPAS. In Seminar Nasional Sains dan Teknologi Informasi (SENSASI) (Vol. 1, No.1

Ickhsan, M., Anggraini, D., Haryono, R., Sahir, S. H., \& Rohminatin, R. (2018). Sistem Pendukung Keputusan Pemberian Kredit Usaha Rakyat Menggunakan Metode 
Weighted Aggregated Sum Product Assesment (WASPAS). JURIKOM (Jurnal Riset Komputer), 5(2), 97-102.

Suginam, S., Nasution, E. S., Lubis, S. U., \& Mesran, M. (2018, October). Sistem Pendukung Keputusan Penerima Bantuan Siswa Miskin Menerapkan Metode WASPAS dan MOORA. In Seminar Nasional Sains dan Teknologi Informasi (SENSASI) (Vol. 1, No. 1).

Wedyawati, V. (2019). Perancangan Sistem Informasi Akreditasi Program Studi Sekolah Tinggi Teknologi Industri (Sttind) Padang. JOISIE (Journal Of Information Systems And Informatics Engineering), 1(2), 95-102.). 